\title{
The effects of differing forms of blank feedback on response repetition in paired-associate learning*
}

\author{
DAVID C. RIMM and KAREN LaPOINTE \\ Southern Illinois University, Carbondale, Ill. 62901
}

The present investigation compared four conditions of blank feedback on response repetition in a paired-associate learning task. In no case was $S$ given feedback of any kind. In one condition $S$ was not told there would be no feedback; in a second condition $S$ was so informed. In a third condition $E$ was out of the room while $\mathbf{S}$ performed the task. In a fourth condition $S$ was told there were no correct answers. Consistent with previous findings, Ss showed a very marked tendency to repeat, given blank feedback. However, the effect of the way in which blank was administered did not approach significance. The findings argue against the view that, when Ss repeat following blank feedback, it is because they interpret blank as a confirmation of their response (i.e., the "silence gives consent" hypothesis, Spence, 1970); the findings support Buchwald's (1969) hypothesis that Ss treat blank as if it were devoid of information value.

Several investigations have found that Ss tend to repeat in the presence of blank feedback (Buchwald, 1962; Levine, Leitenberg, \& Richter, 1964; Spence, $1964,1966 a, b)$. One plausible interpretation has been that Ss interpret such feedback as indicating that their response was correct (Levine et al, 1964; Spence, 1966a, b, 1970), since the natural environment is likely to teach S that "silence gives consent [Spence, 1970]." However, Rimm, Roesch, Perry, \& Peebles (1971) reported the results of a paired-associate experiment, comparing repetition probabilities following blank (silent) feedback and feedback consisting of a redundant verbal reminder of the two response alternatives (the numbers 1 and 2). The principal finding was that both forms of feedback led to appreciable and virtually identical repetition rates. That is, Ss repeated as readily when given nonsilent but informationless feedback as when presented with silent feedback. Whereas $\mathrm{S}$ might well have interpreted the silent feedback as "consent," there was no plausible reason why he should have interpreted the statement " 1 or 2 was correct" as equally confirmatory. Rimm et al concluded that their findings argued against the "blank equals right" hypothesis in favor of Buchwald's (1969) hypothesis that $S$ treats blank as if it had no information value.

The present investigation provides an additional test of the "blank equals right" hypothesis. No S engaging in the paired-associate task was provided with feedback of any kind. Under one condition, $\mathrm{S}$ was not informed that

*This paper is sponsored by R. R. Schmeck, who takes full editorial responsibility for its contents. there would be no feedback. Under a second condition, $\mathrm{S}$ was informed. In a third condition, $\mathrm{E}$ was out of the room "running another subject" while S performed the task. Ss in a fourth condition were told in advance that there were no correct answers. On the assumption that Ss react to blank as if it were truly devoid of information, one would expect approximately equal response repetition rates for all conditions. On the other hand, assuming that Ss do react to blank as if it meant "right" and repeat for that reason, one would anticipate maximum repetition under Condition 1; Ss in this condition would anticipate feedback (initially, at least), which should maximize the tendency to construe E's silence as confirmation. Somewhat less repetition would be expected under the second condition, since $S$ was told to expect no feedback. Under Condition 3, far less repetition would be anticipated since, with $\mathrm{E}$ out of the room, the silence following responding could not possibly be construed as approval. Under Condition 4, a low level of repetition would also be expected, since Ss were told that there were no correct answers.

\section{METHOD \\ Subjects}

Ss were 40 females enrolled in an introductory psychology course at Southern Illinois University, whose participation fulfilled a course requirement. They were assigned randomly to the four experimental conditions.

\section{Materials}

Eight concrete nouns were employed as stimuli, approximately equated for imagery $(I$, mean $=6.0)$, concreteness $(C$, mean $=6.5)$, and meaningfulness $(M$, mean $=6.4)$ and based on the norms of Paivio, Yuille, \& Madigan (1968). Three random orders were presented on a memory drum at the rate of one word per $8 \mathrm{sec}$, with an 8 -sec delay between trials.

\section{Procedure}

Ss in all conditions were provided with the following initial instructions: "Tonight $I$ will be presenting you with a series of words. They will appear one at a time in this window. When a word appears, I want you to respond with the number 1 or 2 . Write the stimulus word and the number 1 or 2 on the card in front of you and then turn the card face down. Do this for each word."

Ss in Conditions 1-3 were also told that " 1 " was correct for half the items and " 2 " was correct for the remainder.

\section{Condition 1}

The $\mathrm{E}$ did hot inform the $\mathrm{S}$ that feedback would not be provided. During the three trials, $E$ sat beside the $S$, making no comment but taking care to observe the S's written response in a conspicuous manner.

\section{Condition 2}

Treatment was identical to Condition 1 , except that the $\mathrm{S}$ was informed at the outset that no feedback was to be provided. 


\section{Condition 3}

After the E had explained the nature of the task, she left the room, informing the $S$ that she had to run another $S$ but would return in $5 \mathrm{~min}$ to collect the data.

\section{Condition 4}

Ss were informed that there were no right or wrong answers. The E remained silent during the completion of the task.

At the conclusion of the experiment, each $S$ was asked if she had found herself repeating the same number and, if this was the case, what prompted her to do so.

\section{RESULTS}

Since there were three trials, the $S$ had two opportunities to repeat responses to given stimulus words. The mean Trial 2 repetition probabilities (i.e., probability of repeating what was given on Trial 1) for Conditions $1-4$ were, respectively, $.650, .763, .825$, and .763. An analysis of variance on the number of items repeated per $S$ reveals that the treatment effect did not approach significance, $F(3,36)=1.41$. The comparable Trial 3 repetition probabilities were $.738, .725, .825$, and .725 , which, with the exception of Condition 3 , were quite close in value to the Trial 2 repetition probabilities. Again the analysis of variance on number of repeated items revealed a treatment effect not approaching significance, $F(3,36)=0.34$.

The next question to be dealt with is whether or not Ss did repeat to a significant degree. Given two response alternatives, chance repetition probability is .500 , and all of the group means for both Trials 2 and 3 are well in excess of this. For the purpose of the present analysis, data were collapsed across groups, since significant treatment effects were not found. A S was classified as a "repeater" if she repeated on five or more of the eight items. Of the $40 \mathrm{Ss}, 30$ were repeaters on Trial 2 $(\mathrm{z}=3.16, \mathrm{p}<.002)$ and 31 were repeaters on Trial 3 $(\mathrm{z}=3.48, \mathrm{p}<.001)$. Thus, the tendency to repeat was highly significant. In terms of the proportion of repeaters (for both trials, .763) and the overall repetition probability (for both trials, .752), it can be seen that the tendency to repeat was very marked indeed.

The degree to which a S did or did not repeat tended to be somewhat consistent, as evidenced by a significant correlation between Trial 2 repetitions and Trial 3 repetitions (product-moment $\mathrm{r}=.447, \mathrm{p}<.01$ ). This is further seen in the Trial 3 repetition probability, given that the $S$ repeated on the second trial, which was .831 , somewhat in excess of the unconditional Trial 3 repetition probability.

\section{Subjective Reports}

When asked whether they had found themselves repeating, 31 of 38 responded with "yes" (report sheets for one Condition $1 \mathrm{~S}$ and one Condition $3 \mathrm{~S}$ were lost), 2 responded with "sometimes," and only 5 said "no." Thus, Ss seemed generally aware of their repetition tendencies. When asked what prompted this behavior, the majority (19 of 31) reported some sort of associational strategy (e.g., use of syllables or meaning),
3 indicated that they desired to be consistent, 2 said they thought they were supposed to be consistent, and the remainder answered to the effect that they repeated because they remembered. None of the 38 Ss gave any indication of having interpreted the lack of feedback in any way.

\section{DISCUSSION}

In the present study, Ss showed marked and approximately equal tendencies to repeat prior responses when they were told nothing about feedback conditions, when they were specifically informed they would not receive feedback, when the $E$ was not even in the room to provide feedback, and when they were told that no answer was correct. While the first condition might have been expected to foster the belief on the part of the Ss that no feedback was a form of affirmation, this was less likely in Condition 2 and, especially, in the last two conditions. In particular, it is not conceivable that $\mathrm{Ss}$ in the E-absent condition repeated $82.5 \%$ of their responses because they attributed the lack of feedback to approval on the part of an unseen and remote $\mathrm{E}$. It is true that $\mathrm{Ss}$ in this condition and in Condition 4 were, in effect, given permission to respond as they wished, but this is by no means equivalent to providing the $S$ with a "right" following a given response.

In terms of self-report, not one $S$ reported construing lack of feedback as approval. Spence $(1966 \mathrm{a}, \mathrm{b}, 1970)$ found that Ss did tend to report interpreting blank as correct, although, as Rimm et al have suggested, it is possible that Ss may repeat for other reasons and later indicate that blank meant "right" as rationalization or justification for their behavior. In the present study, Ss were not asked for their interpretation of the silent feedback since it was desirable to pose the same question to all Ss and, for Conditions 2-4 (especially 3 and 4), the response would have provided little in the way of new information (e.g., a Condition $3 \mathrm{~S}$ might have said "because no one was in the room"). The question was posed in a manner which should in no way have discouraged Ss from indicating that they interpreted the E's silence as approval, but the question also allowed for the reporting of other factors.

As Rimm et al (1971) have argued, it is possible to postulate different mechanisms to account for why Ss repeat when given different forms of blank feedback (or the differing circumstances of silent feedback in the present study), but this is not in the interest of parsimony. If the "blank equals right" hypothesis does not adequately account for repetitions following silent feedback, an alternative is in order. Buchwald's (1969) hypothesis that Ss treat blank as they would "right" or "wrong" feedback which had been forgotten (ergo, blank is truly devoid of information) would account for equal repetition rates across the variety of conditions. Why repetition rates are so high is another matter. It may well be, in the present study at least, that repetition probability closely approximated the probability to recall, which, given a list of only eight items, would probably be well above chance. From the self-reports, Ss did tend to employ strategies to facilitate recall. Having gone to the effort of associating a word and number, in the absence of feedback there was nothing in the situation which would motivate the $S$ to change her response.

\section{REFERENCES}

Buchwald, A. M. Variations in the apparent effects of "right" and "wrong" on subsequent behavior. Journal of Verbal Learning \& Verbal Behavior, 1962, 1, 71-78.

Buchwald, A. M. Effects of "right" and "wrong" on subsequent behavior: A new interpretation. Psychological Review, 1969, 76, 132-143.

Levine, M. K., Leitenberg, H., \& Richter, M. The blank trials law: The equivalence of positive reinforcement and nonreinforcement. Psychological Review, 1964, 71, 94-104. Paivio, A., Yuille, J. C., \& Madigan, S. A. Concreteness, imagery 
and meaningfulness values of 925 nouns. Journal of Experimental Psychology, 1968, 76(1, Pt. 2).

Rimm, D., Roesch, R., Perry, R., \& Peebles, C. The effects of blank versus noninformative feedback and "right" and "wrong" on response repetition in paired.associate learning. Journal of Experimental Psychology, 197i, 88, 26-30.

Spence, J. T. Verbal discrimination performance under different verbal reinforcement combinations. Journal of Experimental Psychology, 1964, 67, 195-197.

Spence, J. T. Effects of verbal reinforcement combination and instructional condition on the performance of problem solving tasks. Journal of Personality \& Social Psychology, 1966a, 3, 163-170.
Spence, J. T. The effects of verbal reinforcement combination on the performance of a four-alternative discrimination task. Journal of Verbal Learning \& Verbal Behavior, 1966b, 5, 421-428.

Spence, J. T. Verbal reinforcement combinations and concept-identification learning: The role of nonreinforcement. Journal of Experimental Psychology, 1970, 85, 321-329.

(Received for publication January 8, 1973.) 